\title{
Micropropagation of Solanum xanthocarpum - to meet the demand of good quality raw material for herbal medicine
}

\author{
${ }^{1,}$ Kilankaje Ashakiran, ${ }^{2,}$ Kuttan Vidya ${ }^{3,}$ Chenni Vettil Sruthi, ${ }^{4,}$ Maniyan \\ Kaithavallapukari Asha, ${ }^{5,}$ Vendamrutham and ${ }^{6,}$ Ambika Sindhu \\ ${ }_{1,2,3,4,5,6,} \& \&$ D Division, The Arya Vaidya Pharmacy (Coimbatore) Ltd., Kanjikode, Kerala, India.
}

\begin{abstract}
Solanum xanthocarpum is one among the 'ten principal medicinal roots' of Indian system of Medicine. Micropropagation through in vitro direct shoot regeneration has been studied in this plant. A combination of BAP $(0.75 \mathrm{mg} / \mathrm{l})$ and Kinetin $(0.25 \mathrm{mg} / \mathrm{l})$ was highly effective in the induction of large numbers (35shoots/callus) of shoots from callus. MS media supplemented with $0.5 \mathrm{mg} / \mathrm{l}$ BAP was best for elongation of in vitro shoots. MS media supplemented with IBA $(0.5 \mathrm{mg} / \mathrm{l})$ was best for the induction and elongation of roots. $95 \%$ of in vitro raised shoots survived during acclimatisation. Hardened tissue cultured S. xanthocarpum plants have flowered uniformly and produced fruits after one month of hardening.
\end{abstract}

Key Words: Solanum Xanthocarpum, In vitro shoot multiplication, root induction, plant growth hormone.

\section{Introduction}

Solanum xanthocarpum schrad \& wendl., which belongs to the family solanaceae, is an important medicinal plant (Rita and Animesh 2011). All the parts of Solanum xanthocarpum are used as traditional Ayurvedic medicinal herb in India. It is used for treating TB, fever, asthma, lung diseases and kidney disorders. The species contain steroids, alkaloids, solasonine and solamargine. Solasonin serves as an important intermediate in the synthesis of steroidal hormones (Butcher 1977) and is a potential alternative to diosgenins as a precursor in synthesis of steroidal hormones (Marck 1989). Fruits, flowers and stems of S. xanthocarpum possess carminative, anthelmintic and bitter properties, root is expectorant and used in treatment of toothache, chest pain due to cough, asthma and bronchitis (Roshy Joseph C 2012). The leaves are applied externally as a pain relieving agent. This plant forms the basis of many polyherbal preparation in the ayurvedic industry (Roshy Joseph C 2012). As there is an increase in the demand of many of these formulations, the reserve of these medicinal plant and herbs are diminishing and are in danger of extinction. The plant tissue culture technique offers mass production of medicinal plants which are genetically homogenous and healthy. Micropropagation via shoot culture, often utilized to maintain clonal fidelity would be a special advantage in this case (Franca et al; 1995). Limited studies have been reported for micropropagation of S. xanthocarpum (Sundar and Jawahar 2011; Saxena et al. 1982; Rahman et al. 2011). Somatic embryogenesis for shoot regeneration of S. surettens was studied by (Ramaswamy et al. 2005). The present study aims to investigate the effect of growth regulators that enhance growth and development to induce multiple shoots in S. xanthocarpum for mass propagation.

\section{Materials and Methods}

2.1 Collection of sample: S. xanthocarpum seeds were obtained from CIMH, Kanjikode, Kerala, India.

2.2 Media Preparation: MS Media was prepared along with different concentrations of plant growth regulators (BAP, IBA, Kinetin). The $\mathrm{pH}$ of the media was adjusted to 5.6 to 5.8 prior to autoclaving.

\subsection{Seed sterilization and Germination}

S. xanthocarpum seeds were soaked in soap solution for 30minutes and were then rinsed in running tap water. This seeds were than washed with distilled water for 3 times and further sterilization was carried out in laminar air flow chamber. The seeds were surface sterilized the with sodium hypochlorite for 5minutes and followed by rinsing with sterile distilled water for 3 times and were invitro germinated on sterilized culture tube containing cotton soaked with sterile water. 


\subsection{Shoot induction and Elongation}

The internodes and nodal segments of in vitro germinated seedlings were used as explants. The explants were inoculated into bottles containing MS media with plant growth regulator BAP of different concentrations $\left(0.25 \mathrm{mgl}^{-1}, 0.5 \mathrm{mgl}^{-1}\right.$, and $\left.1 \mathrm{mgl}^{-1}\right)$ and a combination of BAP and Kinetin $(0.25 \mathrm{mg} / 1$ and 0.75 $\mathrm{mg} / \mathrm{l}, 0.5 \mathrm{mg} / \mathrm{l}$ and $0.5 \mathrm{mg} / 1,0.75 \mathrm{mg} / \mathrm{l}$ and $0.25 \mathrm{mg} / \mathrm{l})$ respectively.

\subsection{Root induction}

The explant derived shoots were excised and sub cultured on MS media with different concentration of plant growth regulator IBA $\left(0.25 \mathrm{mgl}^{-1}, 0.5 \mathrm{mgl}^{-1}\right.$, and $\left.1 \mathrm{mgl}^{-1}\right)$.

\subsection{Acclimatization}

Plantlets with well developed roots were transferred from culture media to poly bag for acclimatization. The roots of the plantlets were thoroughly washed with tap water to remove the nutrient medium. The plantlets were then transferred to poly bags containing soil, sand and organic manure mixture in 1:1:1proportion. The plantlets were initially covered with polyethylene sheets to maintain humidity. Plantlets were watered at an interval of 2 to3 days. The plants were transferred to the open garden soil after 3 weeks for normal growth and development.

\section{RESULTS AND DISCUSSION}

The seed of $S$ xanthocarpum were cultured on MS medium and sterile water soaked cotton. Seed germination was observed after 10 days of inoculation. The percentage of seed germination was found to be higher in sterile water soaked cotton (90\%) (Figure: a). The hypocotyls, internodal and nodal segments of the in vitro raised plant were used as the explants for multiple shoot induction and elongation. The explants were cultured on MS medium supplemented with different combinations of plant growth hormone. Among these, a particular combination of BAP $(0.75 \mathrm{mg} / \mathrm{l})$ and Kinetin $(0.25 \mathrm{mg} / \mathrm{l})$ was significant in the induction of large number of shoots from the callus (35shoots/callus) (Figure: b). Multiple shoot induction and elongation was noted in all the different concentrations of BAP. Among these different concentrations, the rate of response of explants to shoot induction and elongation was found to be higher at $0.5 \mathrm{mg} / 1 \mathrm{BAP}(95 \%)$. The highest number of multiple shoots developed per explant was also obtained at this concentration of BAP. Control media without BAP or kinetin did not induce shoot formation. The explants with multiple shoots were separated and sub cultured on MS medium supplemented with $0.5 \mathrm{mg} / \mathrm{l} \mathrm{BAP}$ at regular intervals for 3-4 weeks (Table 3). The shoots developed on MS media supplemented with BAP were rooted on MS media with IBA of different concentration $(0.25,0.5,1.0 \mathrm{mg} / \mathrm{l})$. Among the different concentration $0.5 \mathrm{mg} / \mathrm{l}$ IBA showed the higher percentage of rooting (Table 4) (Figure: d-f). The control medium (MSO) which is without IBA did not induce rooting. Well developed plantlets were taken out after 30 days and washed with sterile distilled water to remove traces of agar and shifted to polythene cover filled with sterilized soil and manure (1:1). Plantlets were transferred to sack after 3 weeks and maintained in natural condition. The survival percentage of the regenerated plants was found to be $95 \%$ and the plants were similar to wild plants with normal flowering and fruiting (Table 5) (Figure: $\mathrm{m}-\mathrm{p}$ ).

Table 1 Effect of media on in vitro seed germination of S. xanthocarpum

\begin{tabular}{|c|c|c|c|}
\hline Substrates / medium & \% of seed germination & $\begin{array}{c}\text { Length of seedlings } \\
(\mathrm{cm})\end{array}$ & $\begin{array}{c}\text { Size of cotyledon } \\
(\mathrm{cm})\end{array}$ \\
\hline MS solidified agar & $75 \pm 0.5$ & $7 \pm 0.02$ & $4 \pm 0.01$ \\
\hline $\begin{array}{c}\text { Sterile water soaked } \\
\text { cotton }\end{array}$ & $90 \pm 0.5$ & $9 \pm 0.04$ & $5 \pm 0.01$ \\
\hline
\end{tabular}

Table 2. Effect of different levels of BAP and Kinetin on the in vitro multiple shoots induction of $S$. xanthocarpum.

\begin{tabular}{|c|c|}
\hline $\begin{array}{c}\text { MS media + BAP and Kinetin (mg/l) } \\
\text { respectively }\end{array}$ & \% of shoot induction \\
\hline $0.25+0.75$ & $68 \pm 0.5$ \\
$0.5+0.5$ & $70 \pm 0.5$ \\
$0.75+0.25$ & $90 \pm 0.2$ \\
\hline
\end{tabular}


Table 3 Effect of BAP on multiple shoots induction and elongation from the shoot tip explants of $S$. xanthocarpum.

\begin{tabular}{|c|l|l|}
\hline MS media + BAP (mg/l) & Number of shoot/Explants & Shoot length $(\mathrm{cm})$ \\
\hline 0.25 & $15 \pm 0.2$ & $2 \pm 0.1$ \\
0.5 & $35 \pm 0.3$ & $7.7 \pm 0.5$ \\
1.0 & $20 \pm 0.35$ & $5 \pm 0.6$ \\
\hline
\end{tabular}

Table 4 Effect of IBA for root induction in in vitro shoots of S. xanthocarpum.

\begin{tabular}{|c|c|l|}
\hline MS media + IBA (mg/l) & \% of root induction & Root length $(\mathrm{cm})$ \\
\hline 0.25 & $75 \pm 0.4$ & $14.5 \pm 0.3$ \\
0.5 & $95 \pm 0.3$ & $18 \pm 0.2$ \\
1.0 & $80 \pm 0.2$ & \\
& & $9.5 \pm 0.2$ \\
\hline
\end{tabular}

Table 5 Effect of hardening of in vitro raised plantlets of S. xanthocarpum

\begin{tabular}{|c|c|c|}
\hline Potted mixture & Number of plantlets transferred & Survival rate (\%) \\
\hline Soil + manure & 20 & 95 \\
\hline
\end{tabular}

\section{REFERENCES}

[1] Butcher DN (1977) plant tumor cells in plant tissue and cell culture. scientific Publications, Oxford, USA

[2] Marck TK (1989) Invitro culture and the production of Solasodine in Biotechnology in Agriculture, Forestry, Medicinal and Aromatic Plant, vol VII. springer-verlag, Berlin Germany

[3] Rahman MM, Amin MN, Islam MZ, Sultana RS (2011) Mass propagation of Solanum surattense Bum. using direct adventitious shoot organogenesis from internode. Acta agriculturae Slovenica 97 (1):11-17

[4] Ramaswamy N, Ugandhar T, Praveen M, Venkataiah P, Rambabu M, Upendar M, Subhash K (2005) Somatic embryogenesis and plantlet regeneration from cotyledon and leaf explants of Solanum surettens. Indian Journal of Biotechnology 4:414-418

[5] Rita P, Animesh DK (2011) An updated overview on Solanum xanthocarpum schrad and wendl. International Journal of Research in Ayurveda and Pharmacy 2 (3):730-735

[6] Roshy Joseph C IR, Patgiri BJ (2012) THERAPEUTIC POTENTIALS OF KANTAKARI (Solanum xanthocarpum Schrad. \& Wendl.). International journal of ayurveda and allied sciences 1 (2):46-53

[7] Saxena PK, Gill R, Rashid A, Maheshwari SC (1982) Plantlets from Mesophyll Protoplasts of Solanum xanthocarpum. Plant cell Reports 1:219-220

[8] Sundar AN, Jawahar M (2011) In vitro plant regeneration from leaf and stem explants of Solanum xanthocarpum Schrad \& Wendl. - an important medicinal herb Journal of Agricultural Technology 7 (2):301-306
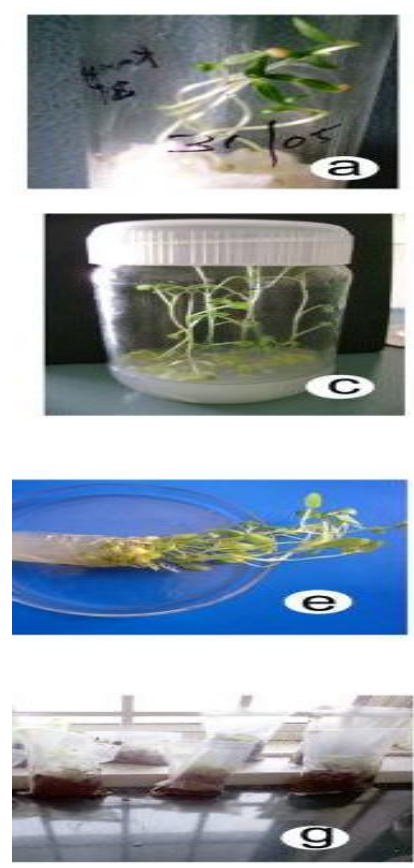

Figure 1 Different stages of In vitro regeneration of S. xanthocarpum
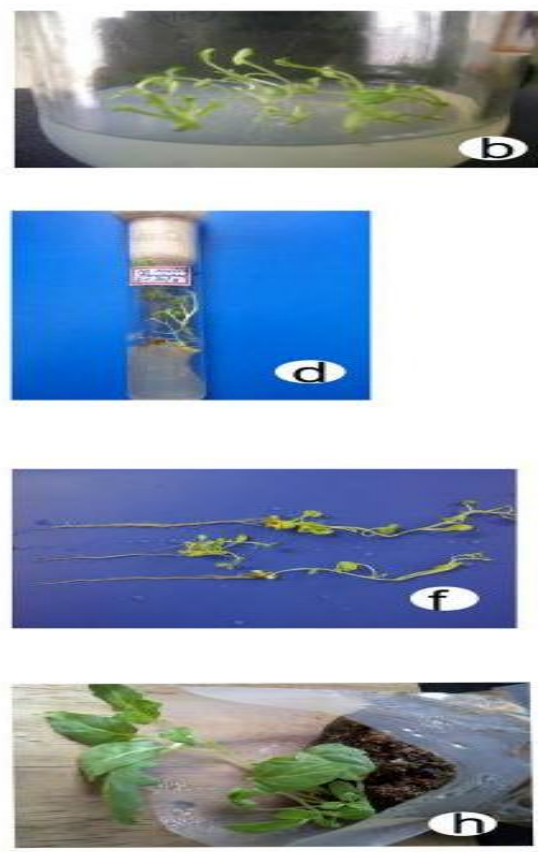

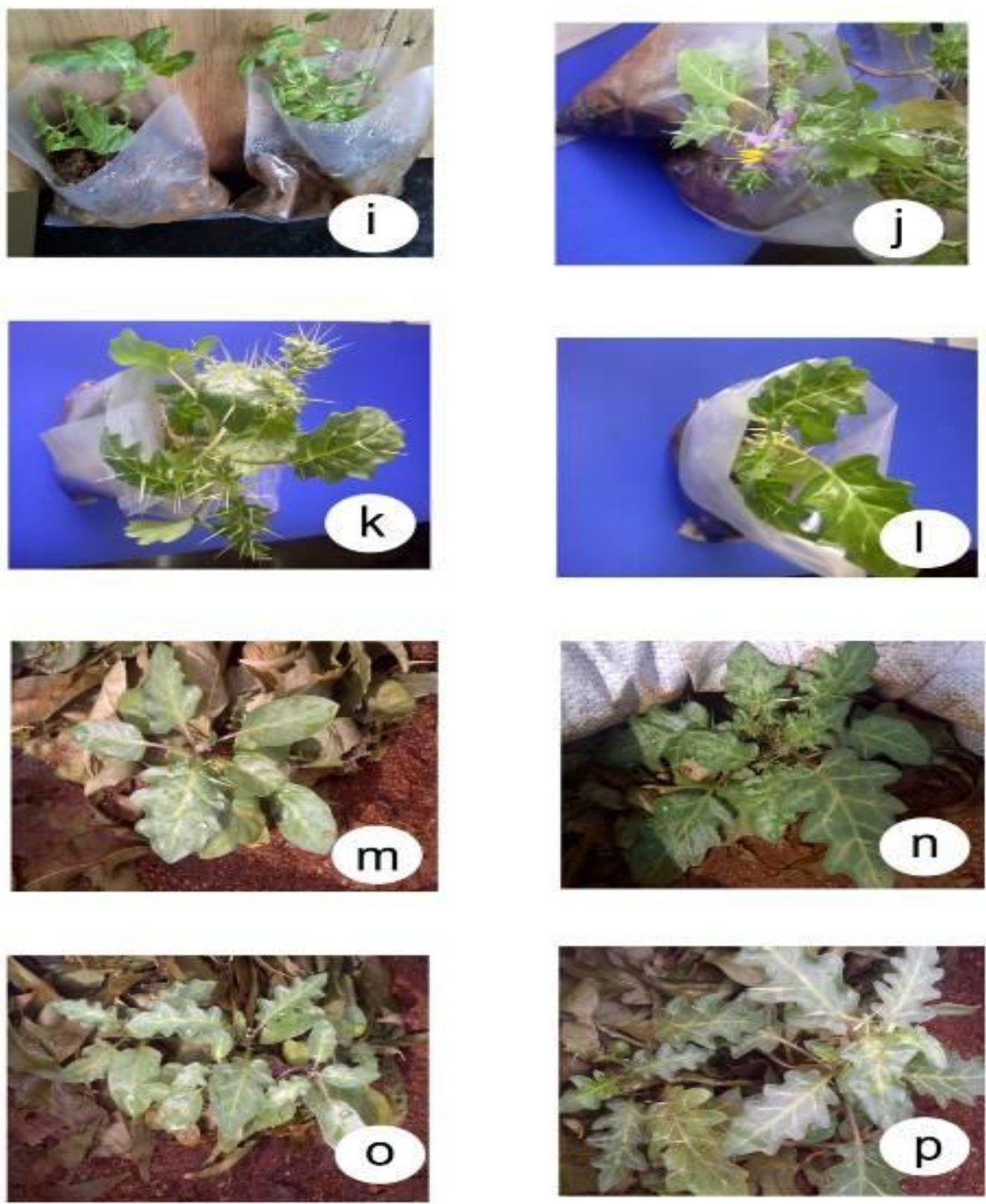

Figure 2 Acclimatized in vitro raised plantlets of $S$. xanthocarpum 